\title{
Cultural Preservations through Digital Reconstruction of Bytul Anwar, Kuala Kangsar, Perak, Malaysia
}

\author{
Noor Hanita Abdul Majid and Zuraini Denan
}

\begin{abstract}
Preservation of heritage building is one of the most important aspects in preserving the cultural identity of a nation. Therefore, the heritage buildings should be documented as it is to conserve old buildings for the future generation. Due to the current state of the heritage buildings and lack of funding many heritage buildings has been left dilapidated. Reconstructing buildings through digital media help to document and preserve the building virtually at minimum cost. The study was conducted on Bytul Anwar that has remained standing from 1912 until now and has undergone transition processes through time. Bytul Anwar was one of the palaces designed by Raja Harun Al-Rasyid who was the crown prince at that time. It is located in the royal compound of Bukit Chandan in Kuala Kangsar that consists of palaces and noble dwellings for the royal family of Perak. This paper presents digital reconstruction of Bytul Anwar and describes the morphology of the buildings from 1912 to 2010 . The reconstruction of the heritage building is based on the following method; interviews, field measurements and computer graphic simulation to reconstruct the house in stages. The research has reconstructed the building digitally to document the additions and renovations including the changes in function of the palace through time. The digital media provides a sound background for documentation and further discussion in cultural heritage.
\end{abstract}

Index Terms-Heritage building, digital reconstruction, palace, architecture morphology.

\section{INTRODUCTION}

Heritage buildings are invaluable in understanding the culture and history of a place and its people. Hence, conservation of the buildings is essential as the reference for the future generations. However, conservation works are costly and can only be undertaken by experts in the field. In order to preserve the heritage buildings, measured drawings can be undertaken to preserve the facts and knowledge of a heritage building. Currently, measured drawings have been practiced by many architecture programs to train students in conservation works and expose them to measurement techniques. The measured drawing course contents propagate the understanding and reasoning behind the spatial layout of the building. The works involved extensive research especially in tracing the missing elements that has undergone changes through time.

The study on Bytul Anwar has unveiled the uniqueness of the buildings that was designed by the crown prince of that time, Raja Harun Al-Rasyid ibni Sultan Idris 1 Mursyidul Adzam Syah. Bytul Anwar has distinctive architectural features and characteristics that were outstanding at that time.

Manuscript received July 5, 2013; revised October 1, 2013.

The authors are with the Dept of Architecture, Kulliyyah of Architecture and Environmental Design, International Islamic University of Malaysia (e-mail: noorhanita@gmail.com, zurainidenan@gmail.com).
It is one of the many houses in the compound of Bukit Chandan in Kuala Kangsar that consists of palaces and noble dwellings for the royal family of Perak [1]. The architecture differs from the local Malay traditional houses in Kuala Kangsar (Fig. 1) in spatial layout, architectural elements and details. The overall design of Bytul Anwar is a mixture of Malay and colonial architecture with and essence of a Royal palace. The spaces incorporated in the building consist of audience hall that is common for Malay palaces but designed at a small scale.

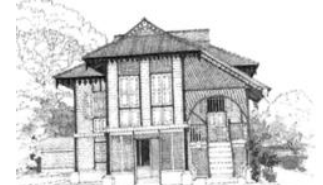

Fig. 1. Typical Malay traditional house design in Kuala Kangsar, Perak

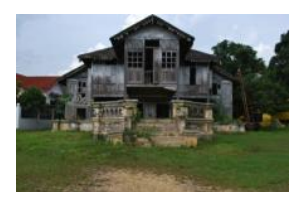

Fig. 2. Dilapidated conditions of the building
Bytul Anwar has many distinctive features such as the sotoh or the roof top balcony and a grand staircase that is different from the common traditional houses. Nevertheless, the current dilapidated state of the building (Fig. 2) has lost some of the distinctive features that was gathered through literature reviews and interviews. This condition has posed a challenge to trace back the changes through the exploring the morphology of the house.

\section{Methodology}

The research gathered data from various methods namely interviews, field measurement and computer graphic simulation. Hence, interviews are conducted with the royal family members and neighbors. The royal family members interviewed are among those who had lived in or frequently visited the building. The information gathered is very useful in reconstructing the image of the palace. The following section presents the transformation of the house from 1912 (Fig. 3), 1915 (Fig. 4), 1920 (Fig. 5), 1930 and 1940 (Fig. 6).

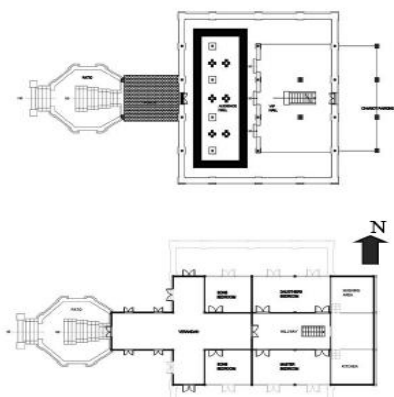

Fig. 3. The house plan in 1912. 


\section{- 1912}

The house starts with a simple plan layout that consist of the veranda, four bed rooms in main house (rumah ibu) and kitchen (dapur) on first floor and halls (balai) on the ground floor. The halls are bordered with half wall on its perimeter. Notice at this time there was a grand staircase linking straight to the first floor.

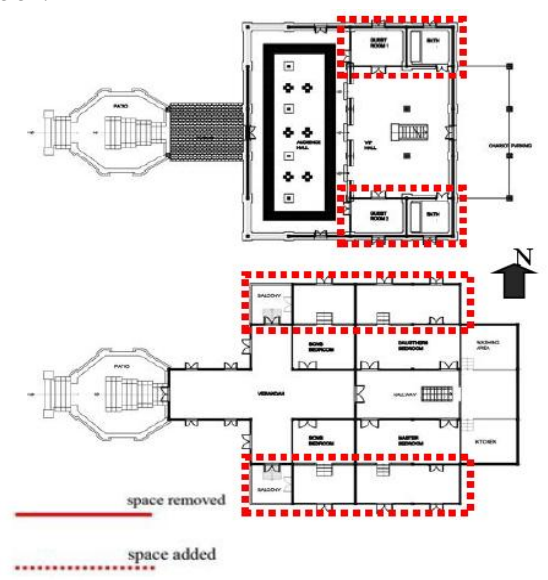

Fig. 4. The house plan in 1915.

\section{- 1915}

The house expands together with the number of family members. There were two more rooms added on ground floor with two bathrooms. The four bedrooms expand with the floor level of the extension spaces drops lower than the original floor level. The window of the sons' bedroom's extension can be linked directly to the roof top. Next to the right and left of serambi are the balconies. At this time, the grand staircase is still intact with iron steel staircases are linked to the rooftop (sotoh).

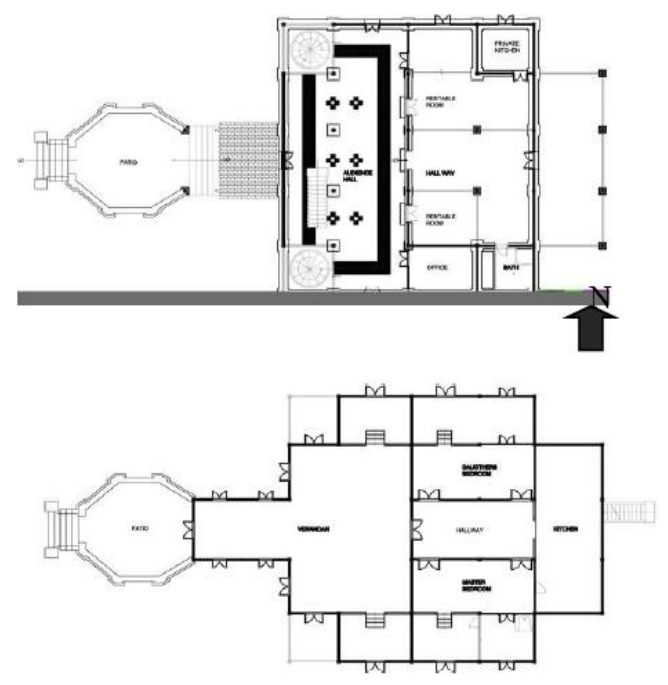

Fig. 5. The house plan in 1920.

\section{- 1920}

Major changes took place with the main stair (tangga batu) case demolished and a brick stair case with timber columns and carvings were added on at porch to the patio. The inner staircase were removed to the audience hall (balai keramaian). The rooftop and balcony was also demolished which results the changes to the audience hall (balai keramaian). Audience hall (balai keramaian) was enclosed by half timber and half brick wall. On the first floor, the two front bedrooms were demolished, and became a wide verandah (serambi). The daughters' and master bedrooms are provided with private staircase to the bathroom in the ground floor.

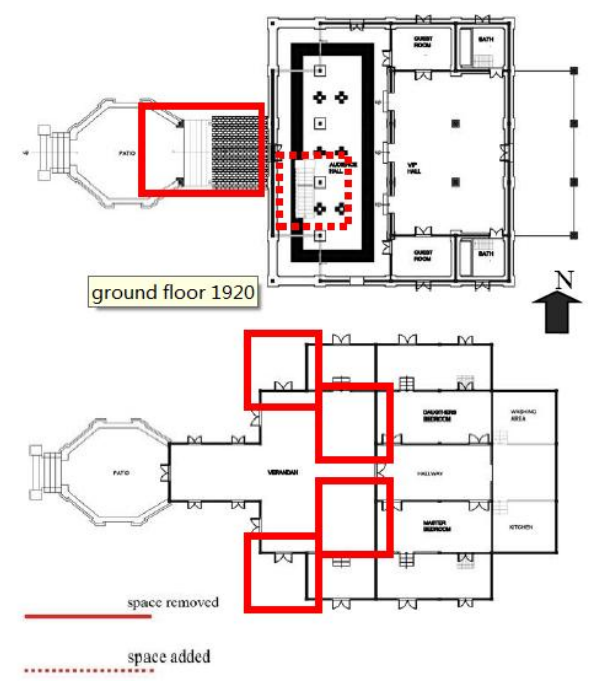

Fig. 6. The house plan in 1940s.

\section{- 1930s to 1940s}

Minor alterations in the house were done to fix the dilapidated part of the house component. There are also some upgrading works to the screen and decorations. Wall panel was changed to iron net. The master bedroom on the right side was provided with a toilet. The right bath room on the ground floor is removed. Windows at the kitchen was removed and extended with fully enclosed wall. The level was changed and a stair was installed to connect directly to the kitchen. The sotoh were re-made but installed with a spiral staircase with fine lattice work.

\section{A. Field Measurement}

The measured drawing is the key data gathering techniques where the existing structure is examined to trace the building morphology through time. It is difficult to reconstruct the real image of the building based on the existing structure and component of the dilapidated building. Based on some literature sources from Arkib Negara (National Archives) and measured drawing report from the University Teknologi Malaysia [2], more data was gathered to trace the real image of the building. The existing structure is measured while tracing back the changes through details found in the building. The measurement become the basis of reconstructing the building images using CAD (computer aided design) and rendered in ATLANTIS. The ruin parts are also reconstructed in the drawing based on information gathered. The measured drawing consists of layout plans, elevations, sections and 3D drawings are documented in Auto CAD software. Figure 7 and 8 show the rendered and line drawings produced through computer simulation [3].

\section{B. Computer Graphic Simulations}

A computer graphic simulation is one of the tools used to simulate the image of the house in 3D specifically using the softwares; Sketch-up and ATLANTIS. Computer graphic simulation was used to present better image and understanding about the building to all level of audiences. A video was also composed to summarize the history, location, image of the palace then and its construction. 


\section{Digital Reconstruction}

Digital simulations have been used to reconstruct the house and record the architecture of the building according to the time line gathered from the interviews [4]-[7]. Table II presents the reconstruction of the two distinct elements that have undergone changes at the building; namely the grand staircase and the roof top balcony or sotoh.

\section{The Grand Staircase}

The grand staircase is one of the distinctive features in the building. It distinguished the building from the common Malay traditional houses in Perak. At a glance the grand staircase maybe a reminder of the front staircase in the traditional houses of Malacca but in Bytul Anwar, the placement and scale of the grand staircase is different. In Bytul Anwar the staircase is placed right in the middle of the front façade as oppose to the Malaccan houses which are on the right or left of the front façade. The grand staircase in Bytul Anwar has a regal scale of being taller due to the height of the ground floor and wider with an added platform at its foot. The straight flight staircase is wider down below and narrower to the top that gives the building and impressive exterior and the illusion of being taller.

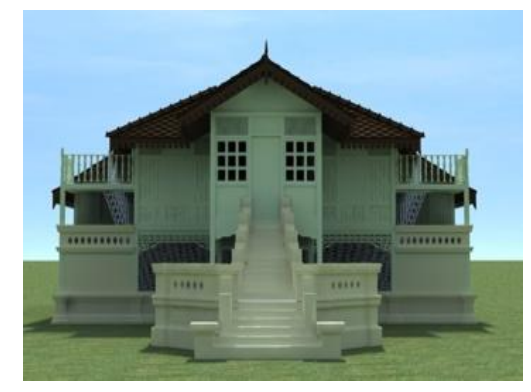

Fig. 7. The rendered version of the front façade.

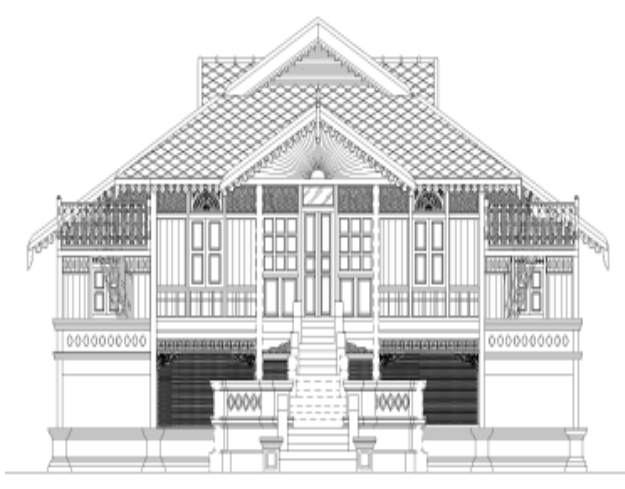

Fig. 8. Drawings showing the line drawings in CAD

Currently the grand staircase is no longer standing except the platform of what used to be the foot of the grand staircase. The door linking to the front staircase has now been changed to a full length window. The platform has been used as a place to enjoy tea in the evening after the removal of the grand staircase in the 1930s-1940s. The stone staircase was constructed out of brick and mortar, and finished with white, yellow and black tiles while the railings were made of a single brick layer with oval shaped balustrades.

Figures in Table I show the reconstruction of the grand staircase in CAD, SKETCH-UP and ATLANTIS program. The digital reconstruction has enabled the building to be viewed as it was in the year 1920. The year 1920 was chosen as the year of reference due to the building's complete state according to the data gathering.

TABLE I: COMPARISON OF BEFORE AND AFTER DIGITAL RECONSTRUCTION

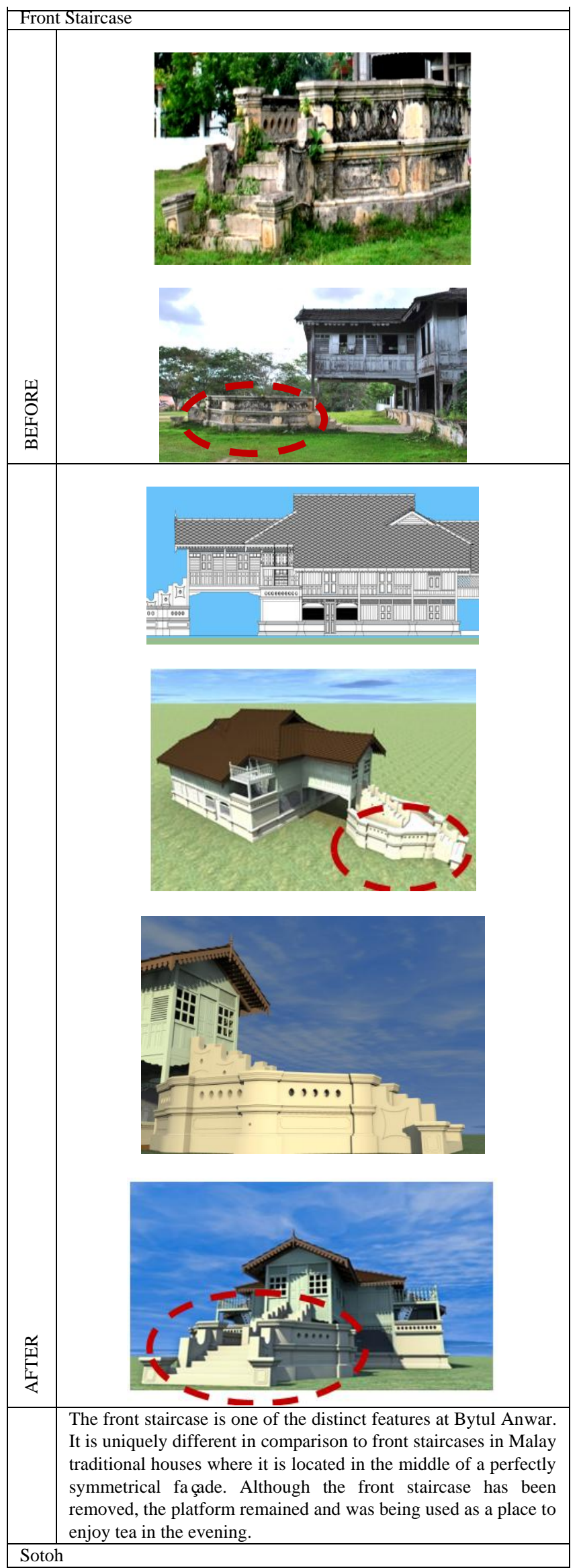



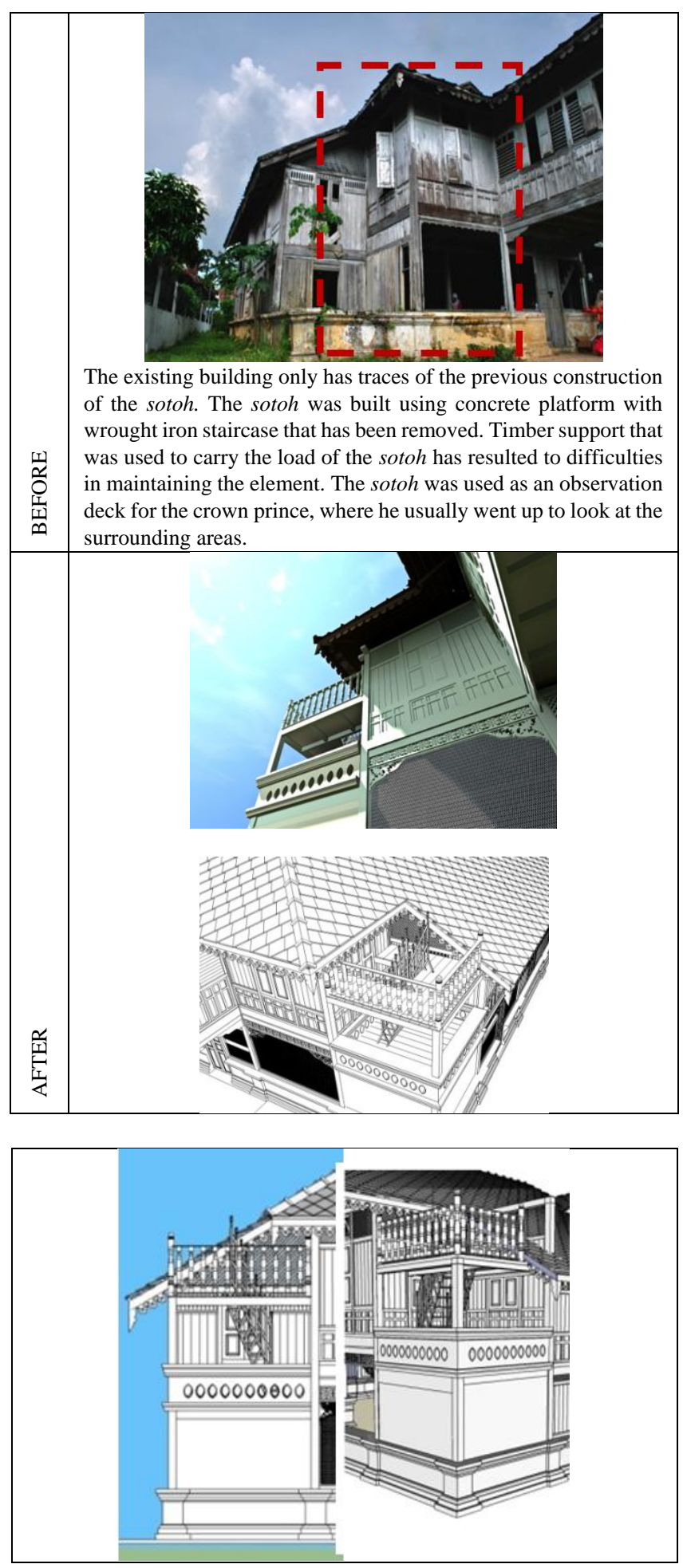

\section{CONCLUSION}

Digital reconstruction is important in recording heritage buildings that has been dilapidated. The research and digital simulation results are important consideration as a tool to record and document what that has been lost through time. The digital reconstruction technique use for Bytul Anwar has enable to record what has been described by the older generations before the previous glory of this distinctive architecture is lost forever.

\section{ACKNOWLEDGMENT}

The research is based on the heritage studies by the students of Bachelor of Science in Architectural Studies (Batch 10). Other lecturers involved were AP Dr. Abdul Razak Sapian and Mohd Suhaimi Ismail.

\section{REFERENCES}

[1] R. N. Shah, Landmark of Perak, RSN Publication Sdn Bhd., 2006.

[2] K. Suja, Baitul Al-Nur Bukit Chandan, Kuala Kangsar, Perak, Measured Drawing, Universiti Teknologi Malaysia, Malaysia, 1979/1980.

[3] Heritage Studies Report on Kuala Kangsar 2010, Heritage Lab, Kulliyyah of Architecture and Environmental Design, IIUM.

[4] C. Zainuddin, Neighborhood Context, 11 April 2010.

[5] R. A. K. B. R. H. A. Rasyid, History of the House, 19 April 2010.

[6] R. H. B. T. Zainal, Function of Bytul Anwar, April 2010.

[7] R. R. B. R. A. Abdullah, Raja Harun Family tree, April 2010.

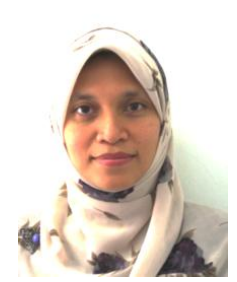

Noor Hanita Abdul Majid is an assistant professor at the Department of Architecture, Kulliyyah of Architecture and Environmental Design, International Islamic University of Malaysia, Kuala Lumpur. She completed her Bachelor and Master degreein the field of architecture at University of Nebraska-Lincoln, USA. Her PhD work is from the University of Teknologi Malaysia where she studied outdoor thermal comfort of urban plazas.

She is a receiver of research awards, i.e Veritas Research Award and Kajima Foundation, Japan and is actively involved in researches besides teaching. Her academic involvolements also covers development and review of curriculum for both Malaysia and Oman.

Dr Noor Hanita is currently involved in researches on passive and sustainable architecture, culture and behaviour, open spaces, housing and heritage buildings. She was involved in Affordable Housing Design at a national level and also some International consultancy works in Makkah and Oman.

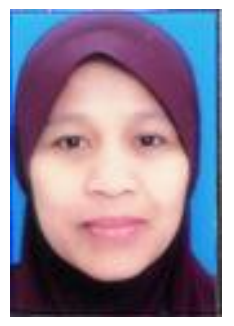

Zuraini Denan is an assistant professor at the Department of Architecture, Kulliyyah of Architecture and Environmental Design, International Islamic University of Malaysia, Kuala Lumpur. She received her Bachelor of Architecture degree from Texas Tech University, Texas, USA and Master degree (MArch) from Universitoi Teknologi Malaysia, Skudai, Johor, Malaysia. Her $\mathrm{PhD}$ work is from the Cardiff University where she studied Visual Comfort (Window and lighting) under Daylight of Office Buildings in Hot Humid Country.

She involves in the review of the Malaysian Standard 2012 under the department of malaysian standard (sirim 2011-2012). She is also a member of passive design group of the japan society for the promotion of science-vice chancellors' council of national universities in malaysia (jsps-vcc, 200-2009). She involves in advising on the daylighting issues at kuala lumpur airport ii under eag consulting sdn bhd.

Besides teaching, she is currently working on several research grants entitled: Empirical Evaluation of Aesthetics Preferences and Environmental Performance of Sun Shading Devices Using Carving of Malay Traditional Houses, The Efficiency of Various Shading Devices in Reducing Glare Under A Hot Humid Daylight in Malaysia and Discovering the architectural significance of Perak Heritage palaces at Kuala Kangsar, Perak. 